heart, liver, and diaphragm), and 9 had low carbohydrate levels in all tissues (usually infants who survived for more than 24 hours). While it could be argued that some of the low values were due to post-mortem changes, this is unlikely to be true of the liver, and lack of liver glycogen could well explain the high incidence of hypoglycaemia in newborn infants; blood samples taken within a few minutes of death from about half the infants in the present series often had a glucose content of less than $4 \mathrm{mg}$. $/ 100 \mathrm{ml}$. Similar blood glucose and liver carbohydrate levels have been observed in lambs and monkeys which had been asphyxiated at birth and then resuscitated (Dawes et al., 1963a), and low cardiac carbohydrate concentrations are found in acute asphyxia (Dawes et al., 1959, 1960, 1963b; Stafford and Weatherall, 1960).

It is reasonable to suppose that skeletal-muscle carbohydrate could be completely depleted in vigorous muscular exercise and that this would explain the exceptionally low values in the diaphragm (Table III B) and rectus abdominis muscles of infants dying in respiratory distress; the diaphragm glycogen fell more rapidly in piglets with distressed respiration than in normal controls (Glauser et al., 1962) and was completely depleted in a premature monkey with severe respiratory distress (Dawes et al., 1963a). Low carbohydrate levels in leg muscle were found only in infants of less than 36 weeks' maturity, where the initial concentration was probably below that at term (Table II), and in mature infants where there was reason to expect unusually low levels at birth, possibly due to placental insufficiency (dysmature infants, infants with grossly unhealthy placentas) or large size (cf. monkey No. 110, Dawes et al., 1960).

Thus it is tempting to suggest that in some cases hypoglycaemia and/or lack of glycogen in a vital organ (heart or diaphragm) may have been the ultimate cause of death. Whereas fat is undoubtedly an important source of energy in normal newborn infants, carbohydrate is probably more important when oxygen is short. But in these circumstances the $\mathrm{pH}$ of the blood and tissues is likely to be low and the intravenous administration of glucose alone may be ineffective or may lead to increased formation of lactic acid and a further fall in pH (Dawes et al., 1963b). Therefore it is advisable not only to administer glucose but also to monitor and correct the arterial $\mathrm{pH}$ in infants where the pulmonary ventilation is impaired.

\section{Summary}

Tissue samples from 14 fresh stillbirths and 116 infants who had died within two weeks of birth, and muscle-biopsy samples from 10 other infants, have been analysed for their total carbohydrate content.

The results obtained from infants dying within four hours of birth suggested that during the last third of pregnancy the foetal liver carbohydrate rises to about twice, and the skeletalmuscle carbohydrate to three to five times, the adult level. The carbohydrate concentration in the heart probably remains at about 10 times the adult level throughout this period.

The carbohydrate levels in the older infants varied with age, maturity, and clinical history. In infants with minimal respiratory distress the liver carbohydrate fell to about $10 \%$ of the level at term within a few hours of birth and the skeletal-muscle carbohydrate fell to adult levels ; there was no abrupt change in cardiac carbohydrate. Much lower values were observed in infants with persistent respiratory distress and the diaphragm carbohydrate was usually exhausted.

Unexpectedly low carbohydrate levels were also observed in babies who were "small for dates" and in three exceptionally large babies.

The results are discussed in relation to other species and to their possible significance.

I am greatly indebted to Dr. Victoria Smallpeice, Dr. Pamela Davies, and Dr. W. A. Aherne, of the Radcliffe Infirmary, Oxford; Dr. G. A. Neligan, of the Department of Child Health, University of Newcastle upon Tyne; and Dr. J. P. M. Tizard and Dr. J. A. Davis, of the Department of Child Health, Hammersmith Hospital, London, for their generous co-operation in this work, both in supplying the samples and in discussing the case histories. I also wish to thank Mrs. Margaret Young for her help in analysing the samples.

\section{REFERENCES}

Bullough, J. (1958). Lancet, 1, 999.

Dawes, G. S., Jacobson, H. N., Mott, J. C., and Shelley, H. J. (1960). f. Physiol. (Lond.), 152, 271.

$--\frac{1}{\text { Tot }}$ and Stafford, A. (1963a). Ibid., 169, 167.

- Mott, J. C., and Shelley, H. J. (1959). Ibid., 146, 516.

-1 and Stafford, A. (1963b). Ibid., 168, 43.

Glauser, E. M., McCance, R. A., and Widdowson, E. M. (1962). Ibid., 161, 313.

Kemp, A., and Kits van Heijningen, A. J. M. (1954). Biochem. F., 56, 646.

Mott, J. C. (1961). Brit. med. Bull., 17, 144.

Searle, C. E., and Woodhouse, D. L. (1958). Biochem. F., 69, 18P.

Shelley, H. J. (1960). F. Physiol. (Lond.), 153, 527.

- (1961). Brit. med. Bull., 17, 137.

Stafford, A., and Weatherall, J. A. C. (1960). F. Physiol. (Lond.), 153, 457.

Szendi, B. (1936). Arch. Gynäk., 162, 27.

Villee, C. A. (1954). Cold Spr. Harb. Symp. quant. Biol., 19, 186.

Wittels, B. (1963). Arch. Path., 75, 127.

JAMES BUCHANAN, M.B., M.R.C.P.ED., M.R.C.P.GLASG.; IAN MURRAY, M.D., F.R.C.P.ED., F.R.C.P.GLASG.

Brit. med. F., 1964, 1, 275-278

Ten years have elapsed since the introduction of insulin zinc suspension ("lente" insulin) to this country. The earlier reports on its use (Lawrence and Oakley, 1953 ; Murray and Wilson, 1953 ; Nabarro and Stowers, 1953 ; Venning, 1954) led to the conclusion that it would effect satisfactory control in more than $80 \%$ of patients requiring insulin. Nevertheless it

* From the Department of Metabolic Diseases, Victoria Infirmary, Glasgow.

† Present address : Royal Hospital for Sick Children, Glasgow. was generally agreed that I.Z.S. proved inadequate in some cases. In a later review (Lancaster and Murray, 1958) it was found that although good results were obtained in $82.5 \%$ of 135 new patients, in only $64.7 \%$ of 201 patients who had previously received some other form of insulin did it prove satisfactory. More recently, Oakley (1961) reported that while good control was obtained in over $80 \%$ of previously untreated cases late results were poor in diabetics requiring high insulin dosage, particularly in young patients. 
In view of these reports it was decided to review the results obtained with I.Z.S. administered over a number of years, and to examine factors which might determine good or bad control. The factors considered were: the duration of diabetes before the start of I.Z.S., age of the patient at onset of diabetes, size of dose, and the incidence of obesity in the prediabetic years. For this purpose a study was made of 211 patients (89 male, 122 female) who attended the Diabetic Clinic at the Victoria Infirmary, Glasgow, during the latter half of 1962, all of whom had begun taking I.Z.S. between 1953 and 1957. All of them might therefore have been taking this insulin for 5 to 10 years, although, as reported below, in many cases it had been discontinued prior to the time of this review.

Classification of the degree of diabetic control is often difficult owing to its variability from time to time. In our previous report (Lancaster and Murray, 1958) we classified the better degrees of control as "excellent" and "good." In the present study, too few patients qualified as excellent to warrant this subdivision. "Good control" was defined as "urine tests normally 'blue' at all times of day but occasionally 'green' or 'yellow, occasional elevated blood sugar, and perhaps the occurrence of mild but infrequent reactions." Blood-sugar estimations were usually made one and a half to two hours after breakfast, and although the level varied it never exceeded 250 mg. $/ 100 \mathrm{ml}$. Admittedly this state of control is not as satisfactory as might be desired, but considering that factors disturbing the balance, such as variation in activity and the occasional dietary lapse, almost inevitably occur, we have accepted it as evidence of at least reasonably good control. In the present report we have continued to use the term "good control" as defined above.

\section{Results}

In 95 of the 211 patients studied I.Z.S. was the first insulin used, while 116 had previously been taking some other insulin. These are designated "new" and "old" patients respectively in Table I, which shows the proportion of cases in which good

TABLE I.-Degree of Diabetic Control with I.Z.S.

\begin{tabular}{|c|c|c|c|c|}
\hline \multirow{2}{*}{$\begin{array}{l}\text { Diabetic } \\
\text { Control }\end{array}$} & \multicolumn{2}{|c|}{ New Patients (95) } & \multicolumn{2}{|c|}{ Old Patients (116) } \\
\hline & Initially & Subsequently & Initially & Subsequently \\
\hline $\begin{array}{l}\text { Good } \\
\text { Fair } \\
\text { Poor } \ldots\end{array}$ & $\begin{array}{c}73(77 \%) \\
14 \\
8\end{array}$ & $\begin{array}{c}45(47 \%) \\
37 \% \\
13\end{array}$ & $\begin{array}{c}71(61 \%) \\
33 \% \\
12\end{array}$ & $\begin{array}{c}41(35 \%) \\
58 \% \\
17\end{array}$ \\
\hline
\end{tabular}

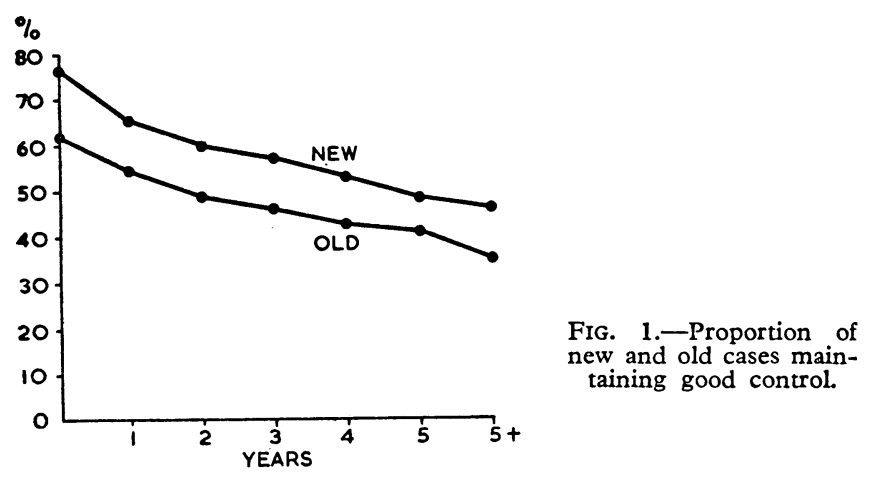

control was obtained. It will be seen from Table I that good control with I.Z.S. was effected initially in $77 \%$ of new patients but only in $61 \%$ of old. In neither group was this success rate maintained, and subsequently - that is, at the present time or when in certain cases described below satisfactory transfer to oral therapy was made-only $47 \%$ of new and $35 \%$ of old cases could be regarded as satisfactory. Fig. 1 shows that the loss of good control occurred at a comparable rate in both new and old cases. If both groups are taken together, the mean success rate falls steadily from an initial $67 \%$ to $42 \%$ after five or more years.

\section{Control Related to Age at Onset of Diabetes}

With the rather arbitrary division of 40 years of age, patients were grouped as of youthful or " maturity-onset " type according to whether diabetes had developed before or after this age. Table II shows the proportion in each group in whom good control was achieved initially and that in whom this was maintained subsequently. Although the initial success rate was much greater $(78 \%)$ in the maturity-onset group than in the younger group (58\%), both showed steady deterioration throughout the next five years. While this is similar in both groups it is seen earlier in children. In Fig. 2 the younger agegroup has been subdivided into patients of 15 to 39 years and those under 15 years. It will be seen that almost half the latter lost good control within the first two years.

TABLE II.-Good Control with I.Z.S. in Young and in "Maturity-onset" Diabetics

\begin{tabular}{|c|c|c|c|c|c|}
\hline \multirow{2}{*}{\multicolumn{3}{|c|}{ Age at Onset }} & \multirow{3}{*}{$\begin{array}{c}\begin{array}{c}\text { No. of } \\
\text { Cases }\end{array} \\
\begin{array}{r}99 \\
112\end{array}\end{array}$} & \multicolumn{2}{|c|}{ Good Control } \\
\hline & & & & Initially & Maintained \\
\hline $\begin{array}{l}\text { Under } 40 \\
40 \text { and over }\end{array}$ & 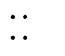 & $\because$ & & $\begin{array}{l}57(58 \%) \\
87(78 \%)\end{array}$ & $\begin{array}{l}29(29 \%) \\
57(51 \%)\end{array}$ \\
\hline
\end{tabular}

Fig. 2.-Good control Fig. 2.-Good control of diabetes.

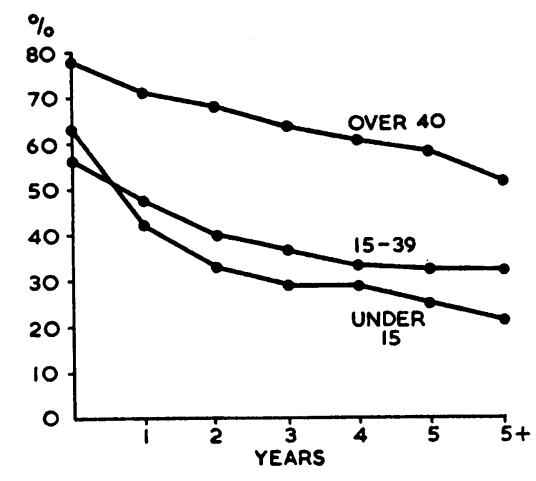

\section{Control Related to Size of Insulin Dose}

As shown in Table III, the best results ( $79 \%$ initially) were obtained in patients requiring less than 40 units. When the insulin requirement was higher the proportion obtaining good

TABLE III.-Good Control Related to Dose of I.Z.S.

\begin{tabular}{|c|c|c|c|c|c|}
\hline \multirow{2}{*}{\multicolumn{3}{|c|}{$\begin{array}{l}\text { Daily Dose of } \\
\text { I.Z.S. } \\
\text { (Units) }\end{array}$}} & \multirow{2}{*}{$\begin{array}{l}\text { No. of } \\
\text { Cases }\end{array}$} & \multicolumn{2}{|c|}{ Good Control } \\
\hline & & & & Initially & Maintained \\
\hline $\begin{array}{l}\text { Less than } 40 \\
40-60 \\
\text { Over } 60\end{array}$ & $\begin{array}{l}\ldots \\
\cdots\end{array}$ & $\begin{array}{l}\ldots \\
\cdots\end{array}$ & $\begin{array}{r}111 \\
53 \\
47\end{array}$ & $\begin{array}{l}88(79 \%) \\
35(66 \%) \\
21(45 \%)\end{array}$ & $\begin{array}{r}60(54 \%) \\
19(36 \%) \\
7(15 \%)\end{array}$ \\
\hline
\end{tabular}

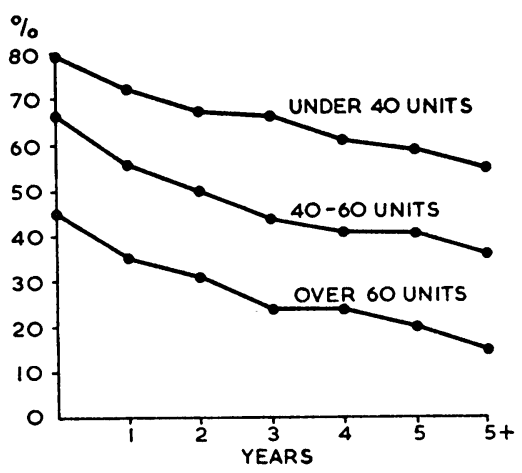

control was less-66\% with 40 to 60 units, and only $45 \%$ when the dose exceeded 60 units. Over the period of observation these proportions declined, and ultimately, despite attempts to improve control by increasing the dose, I.Z.S. maintained good control in only 54,36 , and $15 \%$ of patients requiring less than 40 units, 40 to 60 units, and over 60 units respectively. Again 
the deterioration took place steadily at a rate approximately the same irrespective of the dose of insulin (Fig. 3 ).

\section{Control Related to Previous Obesity}

All patients in this series were at or under their "ideal" weight, as defined by Murray and Wang (1956), when they began taking I.Z.S., but in 65 cases this weight had been exceeded by $10 \%$ or more prior to the development of diabetes. The latter were studied separately and compared with those who had never been overweight. Table IV shows the results obtained both initially and subsequently in these two groups. It will be seen that at first good control was noted in $77 \%$ of those formerly obese compared with $64 \%$ in the others, but that during five years these proportions fell steadily to 55 and $34 \%$ respectively (Fig. 4).

TABLE IV.-Influence of History of Obesity on Good Control

\begin{tabular}{|c|c|c|c|c|c|}
\hline \multirow{2}{*}{$\begin{array}{c}\text { Type of } \\
\text { Case }\end{array}$} & \multirow{2}{*}{$\begin{array}{l}\text { No. of } \\
\text { Cases }\end{array}$} & \multicolumn{2}{|c|}{ Success on I.Z.S. } & \multicolumn{2}{|c|}{ Sulphonylurea } \\
\hline & & Initially & $\begin{array}{l}\text { Main- } \\
\text { tained }\end{array}$ & $\begin{array}{l}\text { Total } \\
\text { Cases }\end{array}$ & $\begin{array}{l}\text { Success- } \\
\text { ful }\end{array}$ \\
\hline $\begin{array}{l}\text { Never obese ... } \\
\text { History of obesity }\end{array}$ & $\begin{array}{r}146 \\
65\end{array}$ & $\begin{array}{l}94(64 \%) \\
50(77 \%)\end{array}$ & $\begin{array}{l}50(34 \%) \\
36(55 \%)\end{array}$ & $\begin{array}{l}18 \\
21\end{array}$ & $\begin{array}{r}2 \\
12\end{array}$ \\
\hline
\end{tabular}

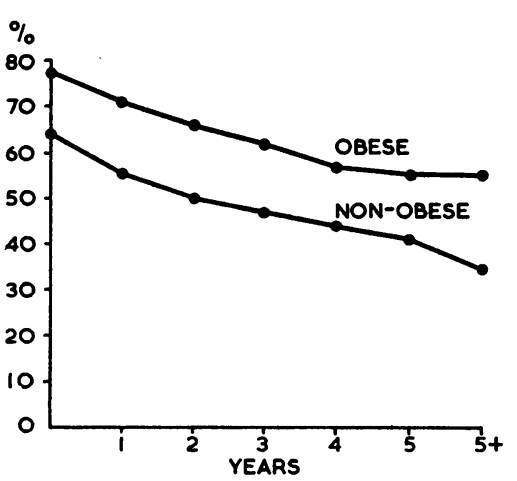

Fig. 4.-Good control related to history of obesity.
The majority of the patients in this survey had started I.Z.S. before the introduction of the sulphonylureas. Had these drugs been available then there is no doubt that some patients would have been given these instead of insulin and would have obtained satisfactory control with this form of therapy. Later, however, transfer to oral therapy was attempted in 39 cases. All were of maturity-onset type, showing excellent control with not more than 40 units of I.Z.S. It is possible that the drugs might with advantage have been tried in a greater number of cases. Some patients were unwilling or afraid to abandon insulin where its effect was so good, and no pressure was brought to bear on them to effect a change. The results obtained with these 39 patients are also shown in Table IV. There was a striking difference in the response shown by the "never obese" group-only 2 successes out of 18 patients, compared with 12 successes out of 21 in the group with a history of former obesity.

\section{Alternative Treatment}

In 21 patients I.Z.S. was continued although the results were not quite satisfactory, since their lack of co-operation was thought to make better control unlikely. In the other cases in which I.Z.S. failed various alternative regimes were tried, and these are summarized in Table V. Patients accustomed to a single daily dose of insulin are naturally anxious to keep to this, and in some cases, where glycosuria was considerable during the day although the fasting state was satisfactory, an attempt was made to improve control by increasing the proportion of I.Z.S. amorphous ("semilente") to I.Z.S. crystalline ("ultralente") to $50 \%$ or more. This was tried in 29 cases, and was successful in 17 . On the other hand, where glyco- suria was marked in the fasting state, increasing the proportion of I.Z.S. crystalline did not prove satisfactory.

TABLE V.-Effect of Change of Insulin on Patients Unsatisfactorily

\begin{tabular}{|c|c|c|c|}
\hline Regime & $\begin{array}{l}\text { No. of } \\
\text { Cases }\end{array}$ & $\begin{array}{l}\text { Now } \\
\text { Good }\end{array}$ & $\begin{array}{c}\text { Still } \\
\text { Unsatisfactory }\end{array}$ \\
\hline $\begin{array}{l}\text { I.Z.S. . } \\
\text { I.Z.S. amorphous/crystailine } \\
2 \text { doses I.Z.S, amorphous } \\
2 \quad \text { ", soluble }\end{array}$ & $\begin{array}{l}21 \\
29 \\
51 \\
20\end{array}$ & $\begin{array}{l}\overline{17} \\
32 \\
12\end{array}$ & $\begin{array}{r}21 \\
12 \\
19 \\
8\end{array}$ \\
\hline
\end{tabular}

Where control was unsatisfactory on a single daily dose, two doses of insulin per day were given, using I.Z.S. amorphous and soluble insulins "tailored" to the patient's individual requirements. In 51 cases I.Z.S. amorphous was used either twice daily or as the evening dose with soluble in the morning. With this regime control became good in 32 . Of 20 patients given soluble insulin morning and night 12 attained good control. By these methods good control was established in 61 cases which had failed with I.Z.S. Adding this number to the 86 patients who maintained good control with I.Z.S. over the period of at least five years, together with two others well controlled on reversion to a mixture of soluble and protamine zinc insulins, it is seen that satisfactory results were obtained in $149(70.6 \%)$ of the 211 patients reviewed.

\section{Discussion}

The results of this investigation closely parallel those of our previous review (Lancaster and Murray, 1958) and show that I.Z.S. administered to new patients can effect good control in about $80 \%$ of cases, but is appreciably less successful in patients transferred to this from some other type of insulin. This difference is perhaps slightly exaggerated, as the "old "patients were a somewhat selected group in that it did not include some who, being well controlled with a soluble and protamine zinc mixture, continued this and were not transferred to I.Z.S., which might have proved equally effective. However, the duration of treatment appears to be definitely related to the efficacy of I.Z.S. as shown by the regular and equal decline in its ability to maintain good control in both new and old patients.

As Oakley (1961) pointed out, I.Z.S. is most effective in older patients with relatively small insulin requirements. This is borne out by the present study. The initial response to I.Z.S. was much better in patients 40 years of age or over, as it was also in those taking less than 40 units, the success rate falling as the dose increased. It is now shown, however, that among both old and young and those with low or high dosage, a similar regular lapse from control with I.Z.S. occurs year by year.

A feature to which little attention seems to have been given in the past is the existence of obesity prior to, but having disappeared at, the time diabetes was diagnosed. This feature appears to be of importance. The fact that a higher proportion of patients with a past history of obesity obtained good control with I.Z.S. than of those without such history, and the strikingly better response they made to oral therapy, suggests that in these individuals diabetes is less severe. Nevertheless it is seen that the proportions controllable with I.Z.S. fall steadily year by year, similarly in both types, and in the same manner as observed in association with the other factors previously considered.

In any assessment of I.Z.S. at the present time account would require to be taken of the wide use of oral therapy. Many patients who would formerly have been given insulin are well controlled by sulphonylureas. Since such patients would have responded successfully to I.Z.S., it follows that when these are excluded the success rate with I.Z.S. must be lower than that reported from the original trials. In the present series, 
exclusion of those transferred successfully to oral therapy leads to a reduction of the ultimate overall success rate from $42 \%$ to $37 \%$, and even this value may be too high, since there may have been others controllable, but untried, with tablets. On the other hand, it should be observed that with I.Z.S., even after continuous administration for more than five years, a large number of patients still maintained good control. This was observed particularly in those with maturity onset $(51 \%)$, those requiring less than 40 units of insulin (54\%), and those who gave a history of former obesity (55\%).

From the results presented it is apparent that more and more patients lapse from I.Z.S. control the longer it is continued. It might be thought that this was due simply to the diabetic state becoming more difficult to control. Good control can, however, be regained in some cases by a change from I.Z.S. to another insulin, whereas it cannot be achieved by increasing the dose of I.Z.S. itself. We suggest that part at least of the explanation of failing control with I.Z.S. is attributable to failure of its crystalline component to exert its desired effect, since its other component, I.Z.S. amorphous, often continues to be of great value.

\section{Summary}

A review was made of 211 non-obese diabetic patients who began taking insulin zinc suspension (" lente" insulin) between 1953 and 1957. Control was better in patients who received I.Z.S. as the first insulin than in those who were transferred from other insulin regimes. It was most readily maintained in patients with maturity-onset diabetes, in those requiring less than 40 units of insulin daily, and in those who gave a history of previous obesity. A sulphonylurea drug was substituted for I.Z.S. in 39 cases, and patients who had been overweight in the prediabetic years showed a strikingly better response than those who had never been obese.

Initially $67 \%$ of all cases were well controlled by I.Z.S. but there was a decrease year by year in the proportion of those who maintained good control. This seemed to be related to the duration of treatment, and after five years only $42 \%$ of cases were satisfactory.

Attempts to obtain better control by other regimes were often successful in those who had failed on I.Z.S., and eventually $70.6 \%$ of all patients achieved good control. The most successful of these methods was two daily doses of insulin. For this purpose I.Z.S. amorphous ("semilente") often proved useful, and it is accordingly suggested that the poor results with I.Z.S. might be attributable to failure of the I.Z.S. crystalline (" ultralente") component.

\section{REFERENCES}

Lancaster, W. M., and Murray, I. (1958). Brit. med. f., 1, 1331.

Lawrence, R. D., and Oakley, W. (1953). Ibid., 1, 242.

Murray, I., and Wang, I. (1956). Diabetes, 5, 49.

- and Wilson, R. B. (1953). Brit. med. F., 2, 1023.

Nabarro, J. D. N., and Stowers, J. M. (1953). Ibid., 2, 1027

Oakley, W. (1961). Proceedings of the Fourth Congress of the International Diabetic Federation, Geneva, 1961.

Venning, G. R. (1954). Lancet, 1, 480.

\title{
Treatment of Severe Decompression Sickness in Aviators
}

\author{
P. CANNON,* $\dagger$ M.B., B.CHIR. ; T. R. GOULD,* $\ddagger$ M.B., B.S.
}

Decompression sickness in aviators is normally relieved by descent to ground-level. In rare cases, however, especially after the onset of severe respiratory or neurological symptoms at altitude, signs and symptoms may persist or recur in spite of immediate recompression to ground-level, leading to the development of post-decompression collapse from circulatory failure (Adler, 1950). Treatment of post-decompression collapse in aviators has formerly been merely supportive (Malette, Fitzgerald, and Cockett, 1962). Conservative treatment, however, while involving prolonged care in hospital, has not prevented persistent sequelae in some cases (Berry, 1961 ; Berry and Smith, 1962), and of 35 cases reviewed by Malette et al. (1962) 16 had a fatal outcome, despite energetic therapy.

The four cases described in this paper developed decompression sickness while undergoing the Royal Naval "highaltitude selection test," which all Fleet Air Arm aircrew are required to do four-yearly. The test consists of exposure to a simulated altitude of $37,000 \mathrm{ft} .(11,277 \mathrm{~m}).(162 \mathrm{~mm} . / \mathrm{Hg})$ in a decompression chamber for three one hour periods on alternate days in one week : $100 \%$ oxygen is breathed throughout. According to the results of this test, aircrew are categorized into three groups. In the majority of cases (category A) there are either

\footnotetext{
* Surgeon Lieutenant, Royal Navy, Royal Naval Air Medical School, Hillhead, Hants.

tNow at the London Hospital.

$\ddagger$ Now at St. George's Hospital, London.
}

no symptoms or these are only minor-for example, pruritus, rash, or fleeting joint pains, not necessitating descent. The second largest group (category B) develop limb pain (the "bends") during the test, and this pain is severe enough to make descent to ground-level necessàry. A small percentage (category C) show signs of severe decompression sickness, developing pulmonary symptoms ("chokes"), signs of central nervous involvement, or syncope. If these severe symptoms persist after descent to ground-level, institution of the most effective method of treatment available is immediately imperative.

Whereas the standard treatment for decompression sickness in divers has always been recompression, and the possible value of compression to greater than one atmosphere absolute in the treatment of aviators' decompression sickness has been suggested on theoretical grounds by Behnke (1955) and others, the first case treated in this way was not reported until some years later (Donnell and Norton, 1960). Since that time a further case has been treated elsewhere by this method (Berry and Smith, 1962), but, in general, conservative treatment has still been regarded as the method of choice.

Since the successful use of compression in the case reported by Donnell and Norton, four further cases of severe decompression sickness in aviators have been treated at the Royal Naval Air Medical School by compression to a pressure greater than one atmosphere. In all four the relief of signs and symptoms was so dramatic that this small series is reported 